\title{
Publisher Correction: Leishmania RNA virus exacerbates Leishmaniasis by subverting innate immunity via TLR3-mediated NLRP3 inflammasome inhibition
}

Renan V.H. de Carvalho (1), Djalma S. Lima-Junior (1), Marcus Vinícius G. da Silva, Marisa Dilucca (1),

Tamara S. Rodrigues, Catarina V. Horta (D), Alexandre L.N. Silva, Patrick F. da Silva (D), Fabiani G. Frantz (D), Lucas B. Lorenzon (1), Marcos Michel Souza (1), Fausto Almeida, Lilian M. Cantanhêde (1),

Ricardo de Godoi M. Ferreira (1), Angela K. Cruz \& Dario S. Zamboni

Correction to: Nature Communications https:/doi.org/10.1038/s41467-019-13356-2, published online 21 November 2019.

The original version of this Article contained errors in Fig. 3, panel L. The second and third lanes should read "L.g.+" and "L.g.-", respectively. These errors have now been corrected in both the PDF and HTML versions of the Article.

Published online: 07 January 2020

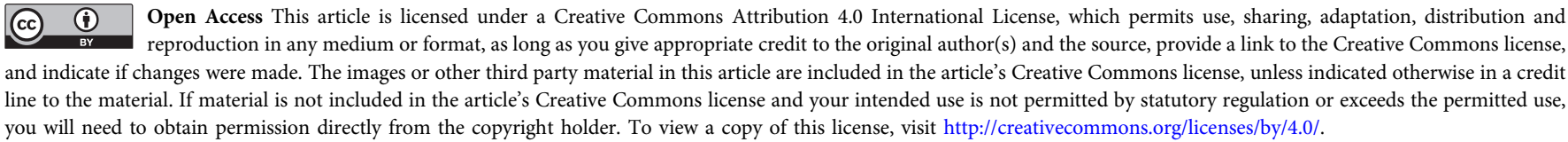

(c) The Author(s) 2020 